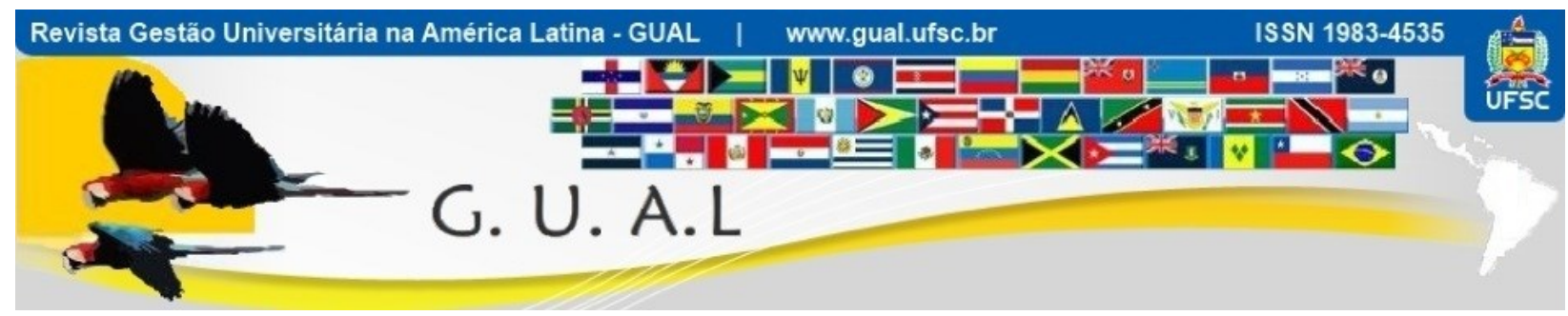

DOI: https://doi.org/10.5007/1983-4535.2021.e73482

\title{
COMUNICAÇÃO INTERNA EM INSTITUIÇÕES PÚBLICAS DE ENSINO SUPERIOR: CANAIS E CONTEÚDOS
}

\section{INTERNAL COMMUNICATION IN HIGHER EDUCATION PUBLIC INSTITUTIONS: CHANNELS AND CONTENTS}

Maria Dionísia dos Santos, Mestre
http://orcid.org/0000-0001-8776-0368
dionisia.santos@ifsertao-pe.edu.br
Instituto Federal de Educação Ciência e Tecnologia do Sertão Pernambucano | Assessoria da Reitoria
Petrolina | Pernambuco | Brasil
Andréa Cardoso Ventura, Doutora
http://orcid.org/0000-0002-4371-632X
andreaventurassa@gmail.com
Universidade Federal da Bahia | Escola de Administração
Salvador | Bahia | Brasil

Recebido em 02/maio/2020

Aprovado em 13/outubro/2020

Publicado em 01/janeiro/2021

Sistema de Avaliação: Double Blind Review

Esta obra está sob uma Licença Creative Commons Atribuição-Uso. 


\title{
RESUMO
}

A comunicação interna vem sendo apontada como uma aliada no fortalecimento das interações, no sentimento de valorização, bem como no engajamento dos colaboradores com as metas e objetivos organizacionais. Assim sendo, este estudo busca analisar a prática da comunicação interna em uma determinada instituição de ensino superior, a fim de mapear as preferências dos funcionários em relação aos canais e conteúdos. Para tanto, foi utilizado o estudo de caso, por meio de uma abordagem predominantemente qualitativa. Concluiu-se que o e-mail é o canal mais utilizado; e que as mídias sociais e os aplicativos de mensagens instantâneas não têm uma boa aceitabilidade, enquanto a comunicação face a face é bem aceita pelos colaboradores. Em relação aos conteúdos, foi apontado o interesse pela divulgação de decisões da gestão, do Conselho Superior, planejamento e assuntos relacionados à gestão de pessoas. Assim, os resultados desta pesquisa pretendem ser uma fonte de assessoramento para que gestores públicos educacionais possam avaliar, definir ou redefinir suas ações de comunicação interna, como também visa ajudá-los a fortalecerem suas interações e relacionamentos com seus públicos estratégicos; e, consequentemente, refletirem de forma positiva na prestação dos serviços ofertados à sociedade.

Palavras-chave: Comunicação Interna. Canais de Comunicação. Conteúdos Comunicacionais. Instituições Públicas de Ensino Superior.

\begin{abstract}
Internal communication is a helpful tool for the strengthening of interactions, the sense of appreciation, and the engagement of employees with organizational goals. Thus, this study seeks to analyze the practice of internal communication in a given higher education institution, in order to map the preferences of the employees in relation to its channels and contents. We used a case study model, through a predominantly qualitative approach. We concluded that email is the most used medium of communication, and that social media and instant messaging applications do not have a good acceptability. Face-to-face communication is also well-accepted by employees. Regarding content, it was pointed out that employees had an interest in the divulgation of management's decisions, as well as those of the Superior Council, and matters related to the management of people. Thus, this research aims to be a source of advice for public educational managers to evaluate or redefine their internal communication, aiming to help them strengthen their interactions and relationships with strategic publics; and, consequently, reflect positively in the services offered to the company.
\end{abstract}

Keywords: Internal Communication. Communication Channels. Communication Contents. Public Institutions of Higher Education. 


\section{INTRODUÇÃO}

As Instituições de Ensino Superior (IEs) públicas têm um importante papel no desenvolvimento social e econômico brasileiro. Elas são responsáveis por formar indivíduos críticos e reflexivos em várias áreas do conhecimento, aptos para atuarem nos diversos setores profissionais. Além disso, as IEs são incumbidas de fomentar o avanço da ciência, da tecnologia, da difusão cultural, bem como do desenvolvimento de atividades de extensão que impactem diretamente nas demandas da sociedade (Brasil, 2006).

Assim, levando em consideração a função social das IEs, este estudo busca contribuir com o fortalecimento desses estabelecimentos de ensino, por meio da discussão e análise da comunicação interna nesse tipo de instituição. Previamente, é preciso compreender que, abarcar essa temática perpassa por entender as IEs públicas como organizações, com características e fins próprios. Conforme afirma Kunsch (1992), as IEs compõem o conjunto das organizações que, por sua vez, integram o sistema social global. Esse grupo de instituições é que possibilita todo o funcionamento da sociedade.

De acordo com Meirelles (2003), pode-se compreender organização como um conjunto de pessoas, métodos e recursos naturais, articulados para um dado fim e balizados por um conjunto de imperativos determinantes (crenças, valores, culturas, etc.). Por sua vez, Cury (2000) conceitua organização como um sistema articulado de esforço coletivo, em que cada membro tem uma função definida a realizar e deveres e atribuições a exercer.

Todavia, é importante destacar que uma organização só é possível por meio da comunicação (BERLO, 2003). É justamente a comunicação entre os componentes que faz do seu conjunto uma organização e não elementos à parte, separados e desordenados. Kunsch (2003) também endossa o pensamento de que a comunicação é inseparável das organizações. Para a autora, o sistema organizacional só se concretiza em virtude do sistema de comunicação que nele existe, o qual possibilita sua retroalimentação e sobrevivência. Ao contrário, as organizações estão sujeitas a um processo de entropia e morte. Sendo assim, pode-se dizer que a comunicação é inerente à organização.

Além do desafio de harmonizar as relações humanas em função de uma finalidade própria, as organizações, atualmente, estão imersas em um universo de incertezas, decorrentes das constantes transformações sociais, econômicas e culturais da era da informação (KUNSCH, 2014). Essas mudanças demandam agilidade e inovação a fim de aproveitarem as oportunidades e enfrentarem as ameaças existentes. 
Diante desse contexto, a valorização do público interno ganha papel de destaque, visto que ele é o responsável por assimilar novos conceitos e práticas que garantam a qualidade do produto/serviço ofertado pelas organizações. Nessa perspectiva, compreender e harmonizar primeiro o espaço interno é fundamental para absorver as intensas modificações de processos (FARIAS, 2009).

Essa conjuntura vem impulsionando novas reflexões e perspectivas para a comunicação nos espaços organizacionais. Atentos a esse novo contexto, muitos teóricos e práticos como Bueno (2009), Curvello (2002), Karanges, Johnston, Beatson e Lings (2015), Kunsch (2009), Marchiori (2008), Matos (2009), Mishra, Boynton e Mishra (2014), Welch e Jackson (2007), Welch (2012), apontam a comunicação interna como uma ferramenta estratégica imprescindível para o diálogo e a interação. Em suas obras, esses autores convergem que ela é uma forte aliada para a valorização e o engajamento dos indivíduos.

Nessa perspectiva, as organizações precisam buscar novas metodologias comunicativas, as quais possibilitem que se evidenciem sugestões, opiniões e o potencial criador do colaborador interno, modificando, assim, os papéis do enunciador e do destinatário, para "uma dinâmica relacional co-autores/criadores" (RIBEIRO e MARCHIORI, 2008, p. 5).

As IEs públicas, como organizações formais e integrantes do sistema social global, também vivem essa realidade. Desta forma, também precisam refletir sobre suas práticas de comunicação interna.

Diante do exposto, e levando em consideração que as IEs públicas, como organizações, têm um papel de extrema importância para o desenvolvimento da sociedade moderna (KUNSCH, 1992), bem como por compreender que a comunicação interna possibilita viabilizar as interações e fortalecer os relacionamentos entre organização e seus colaboradores (MARCHIORI, 2008; WELCH e JACKSON, 2007), este trabalho se propõe a analisar a prática da comunicação interna em uma determinada IE superior, bem como mapear as preferências dos funcionários em relação aos canais e conteúdos, a fim de atender os reais anseios dos colaboradores em relação à comunicação interna.

Desta maneira, a discussão parte do seguinte questionamento: como se configura o planejamento e a execução da comunicação interna em uma determinada IE pública e, na perspectiva de seus colaboradores, quais os meios mais apropriados e conteúdos esperados, a fim de melhorar sua efetividade?

Perante o exposto, pretende-se que os dados obtidos pela investigação sirvam de apoio 
para pesquisadores, profisssionais da área de comunicação e gestores públicos, os quais terão uma fonte de assessoramento para tomar medidas de natureza prática, com vista a avaliarem, definirem ou redefinirem as suas práticas na área de comunicação interna.

\section{COMUNICAÇÃO INTERNA}

A comunicação interna vem sendo percebida como uma área estratégica para as organizações e ganhando espaço no campo das discussões teóricas (KUNSCH, 2009). De forma objetiva, Curvello (2002, p. 22) a conceitua como um "conjunto de ações que a organização coordena com o objetivo de ouvir, informar, mobilizar, educar e manter coesão interna em torno de valores que precisam ser reconhecidos e compartilhados por todos". Contudo, Welch e Jackson (2007, p. 183, tradução própria), afirmam que ainda existem lacunas na teoria e na conceituação da temática e propõe a comunicação interna como "a gestão estratégica de interações e relacionamentos entre as partes interessadas em todos os níveis dentro das organizações".

Em uma linha semelhante, Kunsch (2009) a define como um setor planejado, com fins bem definidos, para viabilizar toda a interação possível entre a organização e seus colaboradores. Endossando esse pensamento, Marchiori (2008) discorre que a comunicação interna promove a interação social e fomenta a credibilidade, agindo no sentido de manter viva a identidade de uma organização. Já Friedl e Vercic (2011) acrescentam que ela tem duas funções principais dentro da organização: informar e fomentar a criação do sentido de comunidade.

A comunicação interna também é apontada como uma oportunidade para valorização dos servidores. Matos (2009) destaca que à medida que o público interno é estimulado a participar e encontra abertura para dar sua opinião, sente-se mais valorizado, motivado e consequentemente mais comprometido com os problemas e objetivos da organização.

Welch (2012) reforça as contribuições entendendo a comunicação interna como uma oportunidade de conscientizar os colaboradores sobre ameaças, oportunidades e prioridades institucionais, além de possibilitar fomentar nos funcionários um sentimento positivo de identificação com a instituição. Por sua vez, Mishra et. al (2014) destacam que a comunicação interna é importante para a construção de uma cultura de transparência, a qual reflete no envolvimento institucional do colaborador. No mesmo sentido, Karanges et. al (2015) concluíram que a comunicação organizacional interna tem um efeito positivo direto no 
desenvolvimento e engajamento dos funcionários, sendo um instrumento que facilita as interações e relacionamentos entre gestores e empregados e abre caminhos para transmitir objetivos e valores institucionais.

Também é válido ressaltar que a credibilidade da instituição perante o mercado e à sociedade é influenciada diretamente pelo público interno. Bueno (2009) destaca que os empregados são os melhores porta-vozes da instituição em que trabalham, porque podem expressar, com mais autenticidade do que outros públicos, os valores positivos ou negativos da cultura organizacional.

Da mesma forma, White, Vanc e Stafford (2010) ressaltam as contribuições positivas que os colaboradores bem informados podem trazer diante do público externo. Colaboradores bem informados são mais propensos a defender instituição e menos predispostos a espalhar boato (CUBBGE, 2005).

Diante do exposto, a comunicação interna pode ajudar as organizações a fortalecerem suas interações e relacionamentos (WELCH e JACKSON, 2007; KUNSCH, 2009), fomentando o sentimento de pertencimento (FRIEDL e VERCIC, 2011; WELCH, 2012), de valorização (MATOS, 2009), e, por conseguinte, o engajamento dos colaboradores com as metas e objetivos institucionais (MISHRA et. al, 2014).

Nesta perspectiva, a comunicação interna assume um papel de relevância estratégica na gestão das organizações, pois ela permite que os colaboradores estejam mais informados, proporcionando-lhe um conhecimento sistêmico dos processos da organização da qual fazem parte e um ambiente de trabalho mais humanizado. Contudo, é importante ressaltar que os ambientes organizacionais são complexos e propícios a disputas, em virtude das singularidades e do confronto de interesses de seus membros (SIMÕES e LIMA, 1997). Assim sendo, a comunicação interna não resolverá todos os problemas institucionais, mas pode se tornar uma forte aliada para auxiliar em um ambiente mais harmônico e interacionista.

\subsection{CANAIS DE COMUNICAÇÃO E CONTEÚDO DE COMUNICAÇÃO INTERNA}

As organizações podem utilizar de vários canais de diferentes formatos para se comunicar e construir relações internas positivas com seus públicos de interesse ou stakeholders. Contudo, Welch (2012) advoga: ao mesmo tempo em que a comunicação pode contribuir para a eficácia das relações organizacionais, ela pode se constituir como uma 
ameaça e tornar-se um fator contraproducente. Para a autora, estes potenciais benéficos dependem de mensagens apropriadas que cheguem aos funcionários em formatos aceitáveis para eles. À vista disso, se os funcionários sentem que a informação é conduzida de forma inadequada, o processo de comunicação poderá danificar as relações internas.

Em linha semelhante, Caleiras (2015, p. 4) destaca a relevância de escolher os meios de comunicação adequados para emitir, de forma direcionada e clara, a mensagem, de acordo com as preferências dos funcionários, afirmando que "[...] quando os meios de comunicação interna são utilizados indistintamente e a todos os níveis gera-se o desinteresse e, consequentemente, uma atitude negativa em todos os colaboradores".

Investigando sobre os canais de comunicação interna, White et. al (2010) indicaram em seus achados que a comunicação dialógica e interpessoal é a preferida pelos colaboradores. A pesquisa apontou que o e-mail é adequado para envio de informações rápidas e atualizações; o site não é considerado um canal de comunicação diária dos colaboradores, mas é um meio importante para arquivo de informações; os documentos impressos, como memorando, ofício, entre outros, significam para os funcionários importância. Já a interação face a face é a indicada para assuntos mais complexos, pois permite o feedback de imediato e a possibilidade de dirimir dúvidas, além de contribuir para o sentido de comunidade e de satisfação do colaborador. As reuniões foram apontadas como um importante canal de comunicação. Contudo, os autores ressaltam que os meios eletrônicos, se usados com cautela, podem ofertar aos funcionários de todos os níveis da organização a oportunidade de saber informações em primeira mão, a partir dos gestores máximos.

Achados semelhantes foram encontrados nos estudos de Men (2014). Os dados mostraram que os colaboradores tendem a ser mais satisfeitos com sua instituição, quando os gestores usam a interação face a face para realizar a comunicação dos assuntos institucionais. Um dado da pesquisa chama atenção: a preferência dos colaboradores pelas mídias tradicionais, em detrimento das mídias sociais, apesar dos funcionários utilizarem muito essas redes em sua vida pessoal.

Contudo, Welch e Jackson (2007) ressaltam que seria ilusório achar que a implantação de uma comunicação interna é algo simples, principalmente em grandes organizações. Nesse sentido, os autores ainda enfatizam que a depender das circunstâncias, os meios de comunicação são uma escolha estratégica imprescindível.

Welch (2012) apresenta três formatos de meios que podem ser utilizados para mediar a 
comunicação interna nas organizações: impresso, eletrônico e face a face. A seguir (Quadro 1), apresentam-se alguns canais, sugerindo os prós e contra.

Quadro 1 Sugestão de possíveis canais de comunicação interna

\begin{tabular}{|c|c|c|c|c|}
\hline Formato & Canal & Público & Prós & Contra \\
\hline Eletrônico & E-mail & $\begin{array}{l}\text { Individual ou } \\
\text { grupal }\end{array}$ & $\begin{array}{l}\text { Rápido; } \\
\text { Barato; } \\
\text { É possível encaminhar } \\
\text { arquivos; } \\
\text { Envio ao grande número de } \\
\text { pessoas. }\end{array}$ & $\begin{array}{l}\text { O receptor pode ignorar a mensagem; } \\
\text { Possibilidade de o leitor não compreender } \\
\text { a mensagem; } \\
\text { Geração de um grande número de } \\
\text { questionamentos que necessitam de } \\
\text { respostas. }\end{array}$ \\
\hline Eletrônico & Intranet & $\begin{array}{l}\text { Restrito aos } \\
\text { membros da } \\
\text { organização }\end{array}$ & $\begin{array}{l}\text { Rápida; } \\
\text { Informações dinâmicas; } \\
\text { Riqueza de multimídia; } \\
\text { Banco de dados; } \\
\text { Transparência ativa. }\end{array}$ & $\begin{array}{l}\text { Funcionário precisa acessar a intranet; } \\
\text { É necessária atualização constante. }\end{array}$ \\
\hline Eletrônico & Videoconferência & $\begin{array}{l}\text { Individual ou } \\
\text { grupal }\end{array}$ & $\begin{array}{l}\text { Econômica; } \\
\text { Atinge pessoas de diferentes } \\
\text { localidades; } \\
\text { Possibilidade de chat; } \\
\text { Pode ser gravada. }\end{array}$ & $\begin{array}{l}\text { Precisa ter uma boa conexão com a } \\
\text { internet; } \\
\text { Podem ocorrer falhas técnicas e afetar a } \\
\text { imagem e som; } \\
\text { Possíveis dificuldades de usar a } \\
\text { ferramenta pelos participantes. }\end{array}$ \\
\hline $\begin{array}{l}\text { Face a } \\
\text { face }\end{array}$ & Reuniões & $\begin{array}{l}\text { Individual ou } \\
\text { grupal }\end{array}$ & $\begin{array}{l}\text { Visão sistêmica da instituição } \\
\text { e de como as decisões são } \\
\text { tomadas; } \\
\text { Possibilidade de dirimir ruídos } \\
\text { de comunicação; } \\
\text { Difundir responsabilidades; } \\
\text { Desenvolvimento do } \\
\text { sentimento de identidade } \\
\text { grupal e de pertencimento } \\
\text { entre os participantes; } \\
\text { Possibilidade de fortalecer o } \\
\text { relacionamento entre } \\
\text { funcionário e gestão }\end{array}$ & $\begin{array}{l}\text { Possibilidade de tornar-se longa e } \\
\text { dispendiosa; } \\
\text { O grupo não ser coeso e a comunicação } \\
\text { não fluir; } \\
\text { Desconforto ao expor a opinião } \\
\text { abertamente. }\end{array}$ \\
\hline $\begin{array}{l}\text { Face a } \\
\text { Face }\end{array}$ & Visita às unidades & Grupal & $\begin{array}{l}\text { Colaborador se sente } \\
\text { valorizado; } \\
\text { Compreender a realidade dos } \\
\text { funcionários; } \\
\text { Comunicação dialógica. }\end{array}$ & $\begin{array}{l}\text { Requer tempo do gestor; } \\
\text { Se tiver várias filiais em diferentes } \\
\text { localidades, é cansativo para o gestor. }\end{array}$ \\
\hline $\begin{array}{l}\text { Face a } \\
\text { face }\end{array}$ & Eventos & Grupal & $\begin{array}{l}\text { Interação grupal; } \\
\text { Sentimento de pertencimento e } \\
\text { comunidade. }\end{array}$ & $\begin{array}{l}\text { Caro; } \\
\text { Logística; } \\
\text { Demanda tempo. }\end{array}$ \\
\hline Impressos & Boletins & Grupal & $\begin{array}{l}\text { Mensagens direcionadas a } \\
\text { públicos específicos; } \\
\text { Credibilidade. }\end{array}$ & $\begin{array}{l}\text { O funcionário pode não ler seu conteúdo; } \\
\text { Custo de impressão; } \\
\text { Preocupações com sustentabilidade. }\end{array}$ \\
\hline Impresso & Cartazes/Mural & Grupal & Visual atraente. & $\begin{array}{l}\text { Mensagens curtas; } \\
\text { Cartazes desatualizados; } \\
\text { Preocupações com sustentabilidade. }\end{array}$ \\
\hline
\end{tabular}

Fonte: Elaboração própria, baseado no formato apresentado por Welch (2012). 
Um ponto também importante para que a comunicação interna alcance seus objetivos institucionais é a quantidade de informação disseminada na instituição pelos superiores. White et. al (2010) ressaltam que é preciso ter um equilíbrio do fluxo comunicacional. Pouca informação pode gerar desconfiança por parte dos colaboradores e impulsionar boatos. Paradoxalmente, o envio em excesso de informações pode causar desinteresse dos colaboradores que passam a ignorar as mensagens.

Diante do exposto, é preciso ter consciência que harmonizar a comunicação interna não é uma tarefa fácil. O público interno não é homogêneo, com características e níveis de necessidades diferentes (GRAY e LAIDLAW, 2002) e, por isso, é preciso traçar estratégias para investigar qual o perfil de seus colaboradores, buscando descobrir: quais são as informações que querem receber; quais são os canais mais adequados para enviar mensagem para seus stakeholders; além de mapear se a quantidade de informações enviadas é adequada.

\section{MÉTODO}

Para o alcance dos objetivos propostos nesta pesquisa, utilizou-se de uma abordagem predominantemente qualitativa e do estudo de caso como estratégia de pesquisa empírica, utilizando as seguintes técnicas de coletas de dados: documentos, observação participante, entrevistas e questionário (conforme apresentado no Quadro 2, abaixo). Apesar de prevalecer uma abordagem qualitativa, o estudo também contou com elementos quantitativos, ao utilizar um questionário para quantificar alguns dados. Pressupõe-se que a junção das abordagens poderá trazer "uma contribuição mútua das potencialidades de cada uma delas, gerando respostas mais abrangentes aos problemas de pesquisa formulados" (DAL-FARRA e LOPES, 2013, p. 77). Os resultados das informações encontradas foram triangulados, para possibilitar que as respostas da pesquisa fossem conferidas.

A pesquisa foi destinada aos servidores técnicos administrativos, docentes e gestores de uma instituição de ensino superior (IE) multicampi, situada no Nordeste. Após aprovação do Comitê de Ética e anuência da autoridade máxima, foi enviado um e-mail, convidando todos os servidores para participarem da pesquisa, por meio de um questionário semiestruturado, com o objetivo de mapear a percepção dos servidores quanto aos canais e conteúdo, além das necessidades de comunicação interna da instituição. Para formulação do questionário, foi utilizado como suporte teórico os seguintes autores: Welch e Jackson (2007), White et. al (2010) e Wen (2014). À época da aplicação, abril de 2017, a população era de 937 servidores e foram obtidas 256 respostas. Assim, obteve-se um percentual de 
aproximadamente $27 \%$ dos colaboradores da Instituição participando da pesquisa.

Para as entrevistas, foram convidados o gestor máximo da Reitoria e os gestores de cinco campi da Instituição, com o objetivo de verificar suas percepções em relação à comunicação interna na Instituição. Foram realizadas entrevistas semiestruturadas com base em um roteiro de perguntas iguais para todos os dirigentes. Também foram entrevistados dois representantes da Coordenação de Comunicação e Eventos da Reitoria. É importante ressaltar que a pesquisa foi realizada por meio das percepções dos participantes, a qual é seletiva e baseada em experiências anteriores dos sujeitos (BERLO, 1985; LEIBNIZ, 1984).

Já a análise documental foi utilizada para apoiar e confrontar os demais dados obtidos, oriundos de outras técnicas aplicadas nesta investigação. Foram consultados os seguintes documentos: Estatuto; Regimento Interno; Relatório de Comissão Própria de Avaliação (2016); e Plano de Desenvolvimento Institucional (PDI). Essa etapa buscou mapear como a comunicação interna é institucionalizada pela gestão e se ela está legitimada nos documentos norteadores e estratégicos da organização. A observação participante foi utilizada naturalmente nesta pesquisa, uma vez que uma das pesquisadoras, coautora do presente trabalho, faz parte do quadro de profissionais da Instituição estudada.

Quadro 2 Estrutura da metodologia da pesquisa

\begin{tabular}{|l|l|l|}
\hline \multicolumn{2}{|c|}{} & \multicolumn{1}{c|}{ Estudo de Caso } \\
\hline FASE 1 & Coleta de Dados & $\begin{array}{l}\text { Técnicas: documentos, questionário, entrevista semiestruturada } \\
\text { e observação participante. }\end{array}$ \\
\hline FASE 2 & Análise dos Dados & $\begin{array}{l}\text { Técnicas: Análise documental e análise sistemática dos dados } \\
\text { encontrados nos questionários e entrevistas. }\end{array}$ \\
\hline FASE 3 & Resultados & $\begin{array}{l}\text { Técnica: Triangulação dos dados, análise descritiva e sugestões } \\
\text { de ações }\end{array}$ \\
\hline
\end{tabular}

Fonte: Elaboração própria.

Os resultados das informações encontradas foram cruzados para possibilitar que as respostas da investigação fossem conferidas a partir de diversificados aspectos. Assim, foi utilizada a triangulação de dados como procedimento de análise. Tal sistemática foi escolhida, pois "tem como objetivo principal o desenvolvimento de linhas convergentes de investigação, proporcionando conclusões mais convincentes e acuradas sobre um mesmo fenômeno" (LYRA; GOMES; JACOVINE, 2009, p. 45). 


\section{RESULTADOS: ENTRELAÇANDO OS DADOS}

Os resultados encontrados foram divididos em quatro tópicos, os quais são apresentados a seguir.

\subsection{ANÁLISE DA PRÁTICA E DO PLANEJAMENTO DA COMUNICAÇÃO INTERNA}

Após análise do Estatuto (2009), Regimento Interno (2011), Relatório de Comissão Própria de Avaliação (2016) e Plano de Desenvolvimento Institucional - PDI (2009-2013 e 2014-2018) foi possível observar que houve alguns avanços em relação à comunicação na Instituição estudada. O número de servidores da área de comunicação cresceu de dois, em 2010, para 30 profissionais, em 2017. Além disso, pode-se citar um processo de evolução da incorporação da comunicação nos documentos institucionais, como, por exemplo, a inserção, a partir de 2014, do eixo Comunicação no PDI.

Entretanto, verificou-se que a Instituição não tinha uma Política de Comunicação, mesmo sendo uma das metas do PDI com prazo de conclusão em 2016. Conforme Kunsch (2003), delimitar uma política de comunicação é primordial, uma vez que ela deverá conduzir toda a comunicação da organização, além de ser responsável por estabelecer os princípios, valores e diretrizes para o relacionamento de uma instituição com seus diversos públicos estratégicos, entre eles seu público interno (BUENO, 2009).

Observou-se que o relatório da Comissão Própria de Avaliação apontou a comunicação entre as unidades que compõem a Instituição, incluindo a Reitoria, tem sido, de acordo com $39,6 \%$ dos respondentes, ruim ou péssima. Para a Comissão, tal resultado demostra que há uma necessidade da IE criar mecanismo de maior "interatividade". A avaliação negativa também foi constatada na presente pesquisa. A média geral sobre a qualidade da comunicação interna entre as unidades ficou em 5,5, em uma nota que poderia variar de 1 a 10 . Tal fato pode se justificar em virtude da Instituição ser multicampi e ter unidades em seis municípios, proporcionando uma dispersão geográfica.

Deste modo, é importante que a Instituição adote novas estratégias para fomentar os espaços de interação face a face, os quais dependem primeiramente de decisão de gestão. Mas é importante frisar, em virtude de sua dispersão geográfica, que os meios de comunicação, os quais são geridos pelos profissionais de comunicação, se tornam imprescindíveis. Portanto, a comunicação interna necessita do alinhamento da gestão e das equipes de comunicação para sua efetividade. 


\subsection{POLÍTICA, ELEIÇÃO E OS REFLEXOS NA PRÁTICA DE COMUNICAÇÃO INTERNA}

Por meio da observação participante e das entrevistas, notou-se um conflito presente na relação entre os servidores de comunicação e os gestores de algumas unidades. Foi possível perceber que os resultados das eleições para Reitor e diretores de campi, realizada um ano e três meses antes da aplicação da pesquisa, ainda estavam presentes e influenciando negativamente no alinhamento da comunicação na Instituição. Membros da equipe de comunicação tinham se posicionado publicamente contrários à gestão vencedora. Mesmo se passando um ano da posse dos dirigentes, era notória a falta de aceitabilidade de alguns membros da comunicação com a gestão e a tensão entre ambas as partes, o que estava dificultando o alinhamento das ações de comunicação dentro da instituição.

O conflito se agravava, também, pelos interesses dos dois grupos: a área de comunicação esperava representatividade política e uma diretoria específica para a área, enquanto que a gestão desejava uma atuação mais efetiva e estratégica da comunicação. A situação encontrada ratifica o exposto por Simões e Lima (1997), afirmando que as organizações são um ambiente político e trazem, por natureza, a possibilidade de conflito, em virtude do confronto de interesses de seus membros e de luta pelo poder.

As entrevistas também deixaram evidente a falta de alinhamento entre os grupos. Conforme trechos de entrevistas abaixo:

\footnotetext{
Os limites que são colocados por alguns profissionais de comunicação é uma grande barreira. Eles compreendem que têm limitações na atuação deles. Reuniões e encontros que impactam na vida dos servidores não são divulgados porque na compreensão deles não é notícia. E a gente recebe uma carga muito grande de cobrança, porque os servidores e a sociedade querem transparência (Gestor 1, relato de entrevista, 2017).

Se a Ascom [referindo-se à Coordenação de Comunicação e Eventos (CCEV) da Reitoria] fosse mais flexível ajudaria bastante a comunicação da nossa unidade (Gestor 2, relato de entrevista, 2017).
}

$\mathrm{Na}$ outra vertente, um dos representantes de comunicação destacou que a comunicação institucional é um desafio diário que os profissionais de comunicação enfrentam para delimitar, pois os servidores confundem o que é comunicação organizacional, com falta de transparência nas rotinas administrativa ou falta de integração entre os setores.

Essa percepção causa uma indevida insatisfação, cuja atribuição é dada ao setor de comunicação institucional. No entanto, o planejamento dos fluxos dos processos administrativos é de atribuição dos gestores de seus 
respectivos setores. O setor de comunicação poderá participar do processo de planejamento de ações para mudança da cultura organizacional orientada pela gestão da organização (Representante da CCEV 1, relato de entrevista, 2017).

\subsection{CANAIS DE COMUNICAÇÃO: PREFERÊNCIA E ACEITAÇÃO POR MEIO DA PERCEPÇÃO DOS SERVIDORES}

Ao investigar por qual canal os servidores têm mais acesso às informações institucionais, verificou-se que o e-mail institucional é a ferramenta que tem uma maior abrangência (96,5\%), seguido do site $(79,7 \%)$. Ressalta-se que era possível marcar mais de uma opção. Um número pequeno de servidores $(3,2 \%)$ acrescentou que fica sabendo das informações por grupos de aplicativo de conversa (whatsapp).

Um dado que também chama atenção é que $13,3 \%$ dos respondentes afirmaram que sabem das informações por pessoas ou canais de comunicação externos, o que pode provocar informações desencontradas, bem como prejuízos à instituição, desde insegurança, rumores a críticas para o público externo, conforme alerta Bueno (2009).

Em relação à frequência de acesso, o e-mail institucional também se sobressai; 98,5\% dos servidores afirmaram que utilizam a ferramenta sempre ou com frequência. $\mathrm{O}$ resultado reitera as observações realizadas por White et. al (2010), que indicaram o correio eletrônico como meio adequado para envio de informações rápidas e atualizações. Coadunando com esses dados, os dirigentes, durante as entrevistas, em sua maioria, também ressaltaram que o e-mail institucional é o canal mais efetivo para transmitir comunicados e encaminhar divulgação de ações institucionais.

Quando perguntados sobre os canais de comunicação interna, a princípio, todos os gestores indicaram apenas os meios eletrônicos. Não falaram sobre impressos e encontros face a face. Só após serem questionados, eles relataram que também utilizam as reuniões para transmitir informações aos servidores. Ao falarem das reuniões, os gestores justificaram que existem dificuldades para realizar encontros face a face, em virtude dos calendários letivos, uma vez que é preciso suspender as aulas para englobar todos os servidores. "A reunião com a comunidade faz tempo que eu fiz. Toma um dia inteiro. Eu tenho que parar a aula" (Gestor 2, relato de entrevista, 2017). Também foi dito que há complexidade ao realizar reuniões conjuntamente com duas categorias distintas: docentes e técnicos administrativos.

Como as reuniões são com todos os servidores. Às vezes se prolonga demais e quando a pauta se volta para a parte pedagógica, eu sinto que há um desinteresse dos colegas técnicos administrativos participarem dos assuntos (Gestor 5, relato de entrevista, 2017). 
Ao tempo em que os dirigentes narravam sobre os meios de comunicação interna, eles também foram apresentando as barreiras de comunicação na utilização desses meios. Sobre o e-mail, os gestores queixaram-se que nem todos os servidores acessam a ferramenta e muitas vezes apagam a mensagem sem ler.

Às vezes envio um comunicado por e-mail. Depois os servidores me encontram no corredor da instituição e me perguntam a mesma informação. $\mathrm{Eu}$ acabo explicando. Mas também recebo muito feedback positivo dos emails enviados (Gestor 2, relato de entrevista, 2017).

Os critérios de publicação de conteúdo da CCEV também foram apontados pela maioria dos gestores como um dos fatores que dificultam a comunicação entre gestão e a comunidade acadêmica, além da falta de interesse do servidor sobre as informações institucionais e as barreiras culturais. "É também uma questão de cultura. A gente precisa internalizar que é preciso passar a informação" (Gestor 1, relato de entrevista, 2017).

Assim sendo, mesmo com as dificuldades postas, é consenso entre servidores e gestão que o e-mail é a ferramenta mais eficaz de comunicação interna atualmente na Instituição. Ainda em relação à frequência de acesso, o site institucional ocupa o segundo lugar, somando $80,1 \%$. Já as ferramentas menos utilizadas são relacionadas às mídias sociais oficiais da instituição: $56,7 \%$ e 94\%,5 dos servidores afirmaram que nunca ou raramente acessam, respectivamente, a página do facebook e o perfil do twitter. Tal resultado reafirma os achados encontrados por Men (2014) em sua pesquisa: os colabores preferem os canais tradicionais às mídias sociais, ainda que as utilizem muito em sua vida pessoal.

Além da baixa aceitação das mídias sociais como ferramenta de comunicação institucional, alguns servidores, no campo do questionário aberto, destinado a realizar críticas ou sugestões, de forma opcional, manifestaram que não legitimam os aplicativos de mensagens instantâneas como meio oficial de transmissão de informação da instituição.

Desconsidero o whatsapp (aplicativo de conversa), enquanto ferramenta legal para a gestão (Servidor 3, relato registrado no questionário, 2017).

Fico sabendo das informações depois que acontecem, pois marcam as reuniões e dão aviso pelo whatsapp (Servidor 4, relato registrado no questionário, 2017).

Acrescenta-se ainda que, com o objetivo de identificar novas ferramentas de comunicação, as quais ajudassem no fluxo de comunicação interna da Instituição pesquisada, foi elencando uma série de novos canais de comunicação para que os servidores indicassem 
quais eles acreditavam que poderiam melhorar a comunicação interna na instituição. Nos resultados, os aplicativos de mensagens instantâneas foram os menos sugeridos pelos servidores. Contudo, nas entrevistas com os gestores, dos seis entrevistados, três afirmaram que suas unidades têm grupos de aplicativos de conversas. Dos três, dois avaliaram de forma negativa o canal. Um dos dirigentes destacou que o grupo não foi criado pela gestão e tem servidores que fazem questão de não participar. O dirigente ainda complementou que já ocorreram problemas de a mensagem não chegar a todos os servidores, e se preocupa com os assuntos que são postos no aplicativo, pois compreende que não é o melhor canal para transmitir informações internas.

Determinadas discussões, pela complexidade, não deveriam ser colocadas lá, e sim discutidas em reuniões. Algumas informações são exageradas. Não acho muito positivo a ferramenta. Já chamei atenção do pessoal do que se coloca nessa ferramenta, para que a nossa unidade não seja prejudicada. Eu acompanho mais do que dou retorno. Faço o máximo possível para não discutir nada dentro no grupo (Gestor 4, relato de entrevista, 2017).

Assim sendo, os resultados encontrados apontam que os aplicativos de mensagens instantâneas não são os mais adequados para fazer circular as informações institucionais de interesse de todos os servidores, pois grande parte dos servidores não aceita o canal como meio oficial. Contudo, os dirigentes entrevistados apontaram que o aplicativo pode ser utilizado para grupos menores de gestão. Mas, mesmo assim, deve ser utilizado para enviar avisos simples, conforme relato: "Internamente, o whatsapp nos ajuda muito. Temos um grupo de gestão e às vezes a gente não consegue usar o e-mail e acaba usando muito o whatsapp" (Gestor 5, relato de entrevista, 2017).

Ao analisar ainda as sugestões dadas pelos servidores sobre qual canal poderia ajudar a otimizar a comunicação interna na Instituição, verificou-se que os fluxos de procedimentos interno foram os mais indicados $(65,2 \%)$, seguidos dos encontros face a face com a Reitora/Pró-reitores $(51,2 \%)$ e com diretor-geral/chefe imediato $(47,7 \%)$. A intranet e os manuais/cartilhas aparecem, respectivamente, com 45,7\% e 44,5\%.

Após o exposto, é possível apreender que a Instituição precisa traçar seus fluxos de seus processos administrativos. Além disso, demonstrou que os servidores têm necessidade de criação de espaços em que se possa realizar a comunicação face a face, confirmando a preferência que os servidores têm de dialogarem presencialmente como os gestores máximos da instituição, como já havia sido apontado por Men (2014) e White et. al (2010). 


\subsection{PREFERÊNCIAS DE CONTEÚDO}

A pesquisa buscou, também, identificar a satisfação dos servidores em relação ao conteúdo das mensagens. Nesse quesito, novamente os canais de comunicação site e e-mail institucional se sobressaíram em relação aos demais, como aqueles que contém os conteúdos mais satisfatórios. Mas apenas 25,4\% disseram estar totalmente satisfeitos com o conteúdo do site e $25,45 \%$ com o conteúdo dos e-mails.

Como já exposto anteriormente, o questionário tinha um espaço para que o servidor registrasse, opcionalmente, críticas, sugestões ou outra informação que achasse relevante sobre a comunicação interna na instituição. Foram deixadas algumas observações em relação à estrutura e o conteúdo do site institucional, as quais são exemplificadas no Quadro 3, abaixo:

Quadro 3 Demonstrativo de observações realizadas pelos servidores sobre o site institucional

\begin{tabular}{|l|l|}
\hline \multicolumn{1}{|c|}{ Críticas } & \multicolumn{1}{|c|}{ Sugestões de conteúdo e estrutura } \\
\hline $\begin{array}{l}\text { "As informações não contemplam todas as áreas e } \\
\text { às vezes repetem as pautas e fotos". }\end{array}$ & $\begin{array}{l}\text { "As ações realizadas, mesmo as de menor impacto, } \\
\text { deveriam ser divulgadas". }\end{array}$ \\
\hline $\begin{array}{l}\text { "É difícil encontrar a informação desejada, é um } \\
\text { labirinto ruim de achar as coisas". }\end{array}$ & "Melhorar o link de busca do site institucional". \\
\hline "Melhorar as postagens de alguns campi”. & "Que os eventos sejam divulgados de forma integrada". \\
\hline $\begin{array}{l}\text { "Falta de eficiência na divulgação das informações } \\
\text { no site institucional". }\end{array}$ & $\begin{array}{l}\text { "Alimentar o site com as informações, em tempo hábil, já } \\
\text { que um canal mais adequado para compartilhar as } \\
\text { notícias, entre todos os campi". }\end{array}$ \\
\hline $\begin{array}{l}\text { "Uma ação importante acontece e alunos e } \\
\text { servidores que poderiam participar ficam sabendo } \\
\text { após o evento". }\end{array}$ & $\begin{array}{l}\text { "Divulgar ações de trabalhos apresentados em eventos. } \\
\text { Divulgar Premiação dos professores". }\end{array}$ \\
\hline
\end{tabular}

Fonte: Elaboração própria.

Em relação ao site, alguns gestores também fizeram observações durante as entrevistas, os quais mostraram-se parcialmente insatisfeitos com o conteúdo apresentados no canal, principalmente para as informações relacionadas ao público interno, conforme relato a seguir:

No site, parte da comunidade acha insuficiente, mas não depende só do gestor. Eles [profissionais de comunicação] criam normativas, como, por exemplo, o servidor participa de um congresso internacional foi apresentar uma pesquisa do campus, trabalha com alunos, e segundo eles eu estou mostrando apenas o servidor. O que não é! A partir do momento que eu divulgo que o servidor está indo para a Europa ou para Estados Unidos, eu estou mostrando que nossa instituição está produzindo pesquisa e sendo reconhecida (Gestor 2, relato de entrevista, 2017). 
Diante do exposto, é possível perceber que a Instituição precisa aprimorar o conteúdo das mensagens do site institucional, levando em consideração o que os seus públicos estratégicos desejam saber. No ensejo, chama-se atenção para o quadro apresentado abaixo (Quadro 4), que traz categorias de informações, as quais os servidores apontaram, no questionário, que sentem mais falta de terem acesso. A maioria é ligada à divulgação de decisões da gestão, do Conselho Superior, sobre o planejamento da Instituição e suas unidades e assuntos relacionados à gestão de pessoas. Assim sendo, cabe à gestão maior e a de cada unidade, em conjunto com a Coordenação de Comunicação e Eventos, alinhar o conteúdo das mensagens e divulgar, de acordo com as necessidades institucionais.

Quadro 4 Demonstrativo de categorias de sugestões de informações para IE, conforme percepção dos servidores

\begin{tabular}{|c|c|}
\hline Categorias & Sugestões de Informações que podem ser compartilhadas nas IEs \\
\hline $\begin{array}{l}\text { Decisões gerenciais da } \\
\text { Reitora e Pró-reitores }\end{array}$ & $\begin{array}{l}\text { Atos administrativos da gestão e atuação do Reitor, dos Pró-reitores, diretores } \\
\text { (atividades que estão desenvolvendo). } \\
\text { As tomadas de decisões, que ocorrem por meio de reuniões com os dirigentes } \\
\text { máximos. } \\
\text { Informações internas sobre o gerenciamento da instituição. }\end{array}$ \\
\hline $\begin{array}{l}\text { Conselho Superior } \\
\text { (CONSUP) }\end{array}$ & $\begin{array}{l}\text { Atas de reunião e decisões dos CONSUP (órgão máximo da instituição, formado } \\
\text { por representantes das categorias de servidores e dos gestores). Relatos das } \\
\text { reuniões do Conselho Superior. }\end{array}$ \\
\hline $\begin{array}{l}\text { Assuntos relacionados à } \\
\text { Diretoria de Gestão de } \\
\text { Pessoas (DGP) }\end{array}$ & $\begin{array}{l}\text { Divulgação das portarias internas. } \\
\text { Orientações referentes a cargos e carreiras, como promoções, tempo, mérito e } \\
\text { qualificação. } \\
\text { Informações sobre capacitações. } \\
\text { Interpretação das leis que regem o serviço público de um modo geral. } \\
\text { Normativas. }\end{array}$ \\
\hline Fluxos internos & $\begin{array}{l}\text { Fluxos processuais e de documentos. } \\
\text { Setores e suas competências. } \\
\text { As rotinas de trabalho e procedimentos. } \\
\text { Funções específicas dos setores dentro da estrutura geral da instituição, por } \\
\text { exemplo, das Diretorias no organograma da Reitoria. }\end{array}$ \\
\hline Planejamento & $\begin{array}{l}\text { Propostas e programas implementados. } \\
\text { Planos e proposta da gestão. } \\
\text { Situação dos projetos em andamento e propostas para implantar melhorias. } \\
\text { Planejamento e metas da instituição. } \\
\text { O processo de implementação das ações. }\end{array}$ \\
\hline Orçamento & Informações sobre a aplicação dos recursos públicos. \\
\hline Eventos & $\begin{array}{l}\text { Informações sobre ajuda de custo para participar de evento. } \\
\text { Transparência nos processos de concessão de bolsas. } \\
\text { Calendário de eventos mensais. } \\
\text { Divulgação da participação de servidores em eventos. }\end{array}$ \\
\hline
\end{tabular}

Fonte: Elaboração própria. 
Dando continuidade aos resultados encontrados na avaliação do conteúdo das mensagens dos canais institucionais, as mídias sociais twitter $(83,3 \%)$ e o perfil da instituição no facebook $(58,2 \%)$ tiveram um alto índice de “indiferente”. Como já apresentado, essas foram as ferramentas apontadas pelos servidores que têm a menor frequência de acesso. Um dado que merece atenção em relação ao conteúdo foi também o alto índice de "indiferente" em relação à reunião com Reitor e Pró-reitores (37,9\%). Ao questionar, na entrevista, a autoridade máxima da reitoria sobre o que achava que tinha proporcionado esse alto percentual de "indiferente", ela relatou que a atual gestão tinha apenas um ano que estava gerindo a Instituição e que, nesse período, só tinha conseguido fazer uma única rodada de visita aos campi, com o objetivo de apresentar a equipe de dirigentes. A gestão ainda complementou que já sabia que era momento de retornar aos campi para dialogar com a comunidade.

\section{CONCLUSÃO}

Os resultados desta pesquisa buscaram, a partir da análise de uma IE em particular, apontar contribuições para a prática da comunicação interna em IEs públicas e, consequentemente, refletir de forma positiva na prestação do serviço ofertado à sociedade. Assim, por meio da investigação, foi possível reafirmar e fortalecer alguns achados já expostos em estudos anteriores, bem como apresentar novas constatações, que podem direcionar estudos futuros mais aprofundados e enriquecer as discussões sobre a temática.

Em relação aos canais de comunicação, pode-se reiterar, conforme pesquisas anteriores de White et. al (2010), que o correio eletrônico é a ferramenta mais utilizada pelos colaboradores e a mais eficaz para o envio de informações rápidas, atualizações, comunicados, bem como encaminhar divulgação de ações institucionais. O site apresenta-se como a segunda opção em relação à abrangência e a frequência de acesso. Já as mídias sociais (facebook e twitter) são os canais menos aceitos e acessados pelos colaboradores como ferramenta de comunicação institucional, apesar de utilizaram em sua vida pessoal, coadunando com o estudo já exposto por Men (2014).

Um outro fator que merece atenção são os encontros face a face. Uma vez que a maioria dos servidores afirmou que acredita que os diálogos presenciais podem ajudar a otimizar a comunicação interna na Instituição, demonstrando, assim, que eles têm necessidade de criação de espaços de diálogos com os gestores. Essa constatação confirma o já apontado por Men (2014) e White et. al (2010), os quais afirmaram que a comunicação face a face é 
bem aceita pelos colaboradores. Assim sendo, as IEs podem utilizar-se da comunicação face a face para promover uma maior aproximação com seus colaboradores, aumentar a confiança e a transparência, bem como utilizá-la para ajudar a minimizar os conflitos internos. Entretanto, os gestores devem ser cautelosos para adequar o conteúdo a ser discutido em cada reunião aos interesses das categorias de servidores ali presentes.

Uma descoberta importante apresentada neste estudo refere-se aos canais. A maioria dos servidores da Instituição estudada não valida os aplicativos de mensagens instantâneas como meio oficial de transmissão de informação, bem como os gestores avaliaram negativamente essa ferramenta. Desta forma, conclui-se que esse canal não é o mais adequado para o envio de informações de cunho institucional, principalmente os grupos de mensagens instantâneas, tendo em vista a falta de aceitabilidade, bem como o risco de trazer ruídos para a comunicação interna institucional.

No que diz respeito ao conteúdo, foi possível traçar algumas linhas de convergências apontadas pelos servidores, os quais informaram ter interesse em notícias relacionadas a: decisões gerenciais; Conselho Superior; assuntos relacionados à Diretoria de Gestão de Pessoas (DGP); planejamento, fluxos internos, orçamento e eventos. No geral, percebe-se que os servidores têm interesse em informações que afetam diretamente sua rotina de trabalho.

Um indicativo também significativo que a pesquisa revelou é que as eleições para os cargos de Diretores-gerais e Reitor refletem de forma negativa no alinhamento da comunicação interna, tendo em vista que existem grupos políticos com interesses diversos, o que pode ser uma barreira complexa de comunicação interna. A investigação ainda constatou que uma comunicação interna efetiva necessita da ação conjunta dos profissionais de comunicação e dos gestores.

Diante do exposto, espera-se que os dados apontados possam ajudar os profissionais de comunicação a realizarem seus planejamentos estratégicos, escolhendo os melhores canais, bem como os conteúdos adequados que atendam às necessidades dos colaboradores. Para os gestores, espera-se que eles utilizem essa pesquisa e a comunicação interna como apoio para compartilhar com os colaboradores os desafios de gerir uma instituição pública de ensino superior, oferecendo-lhes conhecimento sistêmico das metas e objetivos institucionais, bem como oportunizando a valorização de todos nas decisões da organização. O que pode possibilitar um ambiente de trabalho mais participativo, engajado e harmônico. Isso poderá refletir na confiança e na qualidade de vida desses profissionais. 
Portanto, para as IEs, a comunicação interna pode ajudar na melhoria do ambiente de trabalho, possibilitando que os profissionais exerçam suas atribuições de forma mais satisfatória e menos estressante, o que refletirá na qualidade das ações desses agentes e, consequentemente, para um futuro melhor da educação pública brasileira. É importante frisar que esta pesquisa tem suas limitações: não foi possível, em virtude do tempo, abarcar nesta investigação todos os públicos internos que compõem a instituição, como os funcionários terceirizados e estagiários, os quais também são responsáveis pela prestação de serviço, além dos alunos.

Por fim, acrescenta-se que novas pesquisas podem ser realizadas, a fim de enriquecer as discussões da comunicação interna nas instituições de ensino superior. Como sugestão, propõe-se: ampliar a investigação abrangendo os públicos internos presentes nessas instituições; realizar o confronto dos dados desta pesquisa com outras instituições de ensino; bem como realizar pesquisas de percepção de satisfação com a comunicação interna, assim como sobre a redução da existência de conflitos, obtendo-se controles antes e depois da implantação de sugestões apresentadas no presente estudo.

\section{REFERÊNCIAS}

BERLO, D. K. O Processo da Comunicação. São Paulo: Livraria Martins Fontes, 1985.

BERLO, D. K. O Processo de Comunicação: introdução à teoria e à prática. São Paulo: M. Fontes, 2003.

BRASIL, República Federativa (1996). Lei 9.394, de 20 de dezembro de 1996. Estabelece as Diretrizes e Bases da Educação Nacional.

BUENO, Wilson da Costa. Comunicação empresarial: políticas e estratégias. São Paulo: Saraiva, 2009.

CALEIRAS, Maria Cândida Rodrigues (2015). Comunicação Interna na Novartis.

(Dissertação de Mestrado). Escola Superior de Educação de Coimbra, Coimbra, Portugal.

CUBBAGE, A. K. (2005) Inside Voices, Currents, Vol. 31, pp. 14-19.

CURVELlO, J. J. A. Comunicação Interna e Cultura Organizacional. São Paulo: Scortecci, 2002.

DAL-FARRA, Rossano André; LOPES, Paulo Tadeu Campos. Métodos mistos de pesquisa em educação: pressupostos teóricos. Nuances: estudos sobre educação, Presidente Prudente - SP, v. 24, n. 3, 2013, pp. 67-80, set./dez. Disponível em: 
http://revista.fct.unesp.br/index.php/Nuances/article/view/2698/2362 (Acessado: 18 de maio de 2016).

FARIAS, Luiz Alberto. O Campo Acadêmico do Ensino e da Pesquisa em Comunicação Organizacional e Relações Públicas no Brasil. In: KUNSCH, Margarida M. Kroling (Eds.). Comunicação Organizacional: histórico, fundamentos e processos (pp. 43-59). São Paulo: Saraiva, 2009.

FRIEDL, J.; VERCIC, A. T. (2011). Media preferences of digital natives internal communication: A pilot study. Public Relations Review, 37(1), pp. 84-86. Disponível em: https://www.sciencedirect.com/science/article/pii/S0363811110001311 (Acessado: 18 de maio de 2016).

GRAY, J.; LAIDLAW, H. (2002). Insider Perspectives on Communication Satisfaction. Australian Journal of Communications, V. 29, n. 3, pp. 111-124.

KARENGES, Emma; JOHNSTON, Kim; BEATSON, Amanda; Lings, Ian (2015). The influence of internal communication on employee engagement: A pilot stady. Public Relations Review, 41(1), pp. 129-131.

KUNSCH, Margarida M. Krohling. Comunicação Organizacional: contextos, paradigmas e abrangência conceitual. Matrizes (USP), V. 8, n. 2, 2014, pp. 35-61.

KUNSCH, Margarida M. Krohling (Org.). Comunicação Organizacional: histórico, fundamentos e processos. São Paulo: Saraiva, 2009.

KUNSCH, Margarida M. Krohling. Planejamento de Relações Públicas na Comunicação Integrada. São Paulo: Summus, 2003.

KUNSCH, Margarida M. Krohling (1992). Universidade e Comunicação na edificação da sociedade. São Paulo: Loyola.

LEIBNIZ, Gottfried Wilhelm. Novos Ensaios sobre o entendimento humano. Tradução de Luiz João Baraúna. São Paulo: Abril Cultural, 1984, Coleção Os Pensadores.

LYRA, M. G.; GOMES, R. C.; JACOVINE, L. G. O papel dos Stakeholders na sustentabilidade da empresa: contribuições para a construção de um modelo de análise. Curitiba: ANPAD / RAC, 2009.

MARCHIORI, M. Comunicação Interna: um fator estratégico no sucesso dos negócios. In: MARCHIORI, M. (Org.). Faces da Cultura e da Comunicação Organizacional (pp. 205222). São Caetano do Sul: Difusão, V. 1, Série Comunicação Organizacional, 2008.

MATOS, Gustavo Gomes. Comunicação empresarial sem complicação: como facilitar a comunicação na empresa pela via da cultura e do diálogo. Barueri - SP: Manole, 2009.

MEIRELES, Manuel. Teorias da Administração: clássicas e modernas. São Paulo: Futura, 2003. 
MEN, Linjuan Rita (2014). Strategic Internal Communication Transformational Leadership, Communication Channels, and Employee Satisfaction. Management Communication Quarterly, V. 28 (2), pp. 264-284.

MISHRA, K.; BOYNTON, L.; MISHRA, A. (2014). Driving Employee Engagement: The Expanded Role of Internal Communications. International Journal of Business Communication, V. 51 (2), pp. 183-202.

RIBEIRO, Regiane; MARCHIORI, Marlene. Comunicação Organizacional Dialógica: uma perspectiva de interação nas organizações. $A L A I C$ - Associación Latinoamericana de Investigadores de Comunicación, IX Congresso Latinoamericano de investigación de La comunicación, pp. 1-14, Ciudad de Mexico, 2008. Disponível em: http://www.uel.br/grupoestudo/gefacescom/images/Congresso_01_ALAIC_2008.pdf (Acessado: 30 de abril de 2016)

SIMÕES, Roberto Porto; LIMA, Suzy Mary do Nascimento. Relações Públicas e micropolítica: um estudo comparativo de seus processos e programas. Revista FAMECOS, Porto Alegre, n. 7, 1997.

WELCH, M. (2012). Appropriateness and acceptability: Employee perspectives of internal communication. Public Relations Review, 38, pp. 246-254.

WELCH, M.; JACKSON, R. P. (2007). Rathinking internal communication: a stakeholder approach. Corporate Communications: An International Journal, 12 (2), pp. 177-198.

WHITE, C.; VANC, A.; STAFFORD, G. (2010). Internal Communication, Information Satisfaction, and Sense of Community: The Effect of Personal Influense. Journal of Public Relations Research, 22 (1), pp. 65-84. 